\title{
PRODUKTIFITAS PRIMER DAN KELIMPAHAN IKAN LAYANG (Decapterus spp.) HUBUNGANNYA DENGAN FENOMENA ENSO, DI SELAT MAKASSAR BAGIAN SELATAN
}

\author{
Primary Productivity and Abundance of Scads (Decapterus spp.) Its Relation \\ With Enso in The Southern Part of Makassar Strait
}

\author{
Oleh: \\ Andhika P. Prasetyo ${ }^{*}$ dan Suwarso ${ }^{2}$ \\ ${ }^{1}$ Pusat Riset Perikanan Tangkap, Jl. Pasir Putih I Ancol Timur Jakarta PO BOX 14430 \\ 2 Balai Riset Perikanan Laut, Jl. Muara Baru Ujung Komp. Pelabuhan Perikan Samudra. Jakarta Utara 14440 \\ Email: dhika_fishery@yahoo.com
}

Diterima: 8 Juni 2010; Disetujui: 5 September 2010

\begin{abstract}
Two species of scad fish (Decapterus russelli and D. macrosoma) is a major catch of purse seine in almost fishing area, its contributed approximately 58\%. Production data of scad fish is based on catch data of purse seine which having fishing base in Java (2006-2007). Chlorophyll-a concentration, sea surface temperature and Photosyntetic Available Radiation (PAR) was derived from satellite imagery AQUA MODIS. That data is used to estimate primary productivity with Vertically Generalized Production Model (VGPM). The effect of ENSO (EI Niño-Southern Oscillation) to scad fish fisheries also discussed. This research is aimed to get information about the effects of ENSO to primary productivity and abundance of scads in the southern part of Makassar Strait. Results showed scad fish abundance in the waters of the southern Makassar Strait fluctuates according to season, the peak abundance lasted for three months between November to January. Utilization of scad fish as $3^{\text {th }}$ tropic level component showed percentage of utilization is $8,93 \%$ in 2006 and $14,59 \%$ in 2007. AQUA MODIS image data showed the highest chlorophyll concentrations occurred between February to April each year. While the highest sea surface temperature occurs in November-January period. There are indication that ENSO have indirect effect to chlorophyll-a consentrations and sea surface temperature. Both of them having relations with scad fish abundance in Makassar Strait.
\end{abstract}

Key words: abundance, ENSO, Makassar Strait, primary productivity, scad fish (Decapterus spp.)

\section{ABSTRAK}

Dua species ikan layang (Decapterus russelli dan D. macrosoma) merupakan hasil tangkapan utama pukat cincin hampir di setiap daerah penangkapan, kontribusinya kira-kira $58 \%$. Data produksi ikan layang yang dikaji berasal dari data hasil tangkapan pukat cincin yang berbasis di Jawa (2006-2007). Adapun data kandungan klorofil-a, suhu permukaan laut dan Photosyntetic Available Radiation (PAR) yang berasal dari citra satelit AQUA MODIS digunakan untuk menduga nilai produktifitas primer dengan Vertically Generalized Production Model (VGPM). Penelitian ini bertujuan mengetahui pengaruh fenomena ENSO terhadap produktifitas primer dan kelimpahan ikan layang di Selat Makassar bagian selatan. Hasil kajian menunjukkan kelimpahan ikan layang berfluktuasi menurut musim, puncak kelimpahan berlangsung selama 3 bulan antara bulan November sampai Januari. Adapun pemanfaatan sumber daya ikan layang sebagai komponen trofik pada level 3 menunjukan persentase pengupayaannya sebesar $8,93 \%$ pada tahun 2006 dan 14,59\% pada tahun 2007. Data citra AQUA MODIS menunjukkan konsentrasi klorofil-a tertinggi terjadi antara Februari-April tiap tahunnya. Sedangkan puncak suhu permukaan laut terjadi pada 
periode November-Januari. Ada indikasi ENSO berpengaruh secara tidak langsung terhadap konsentrasi klorofil-a dan suhu permukaan laut, dimana nantinya berhubungan dengan kelimpahan ikan layang di Selat Makassar.

Kata kunci: kelimpahan, ENSO, Selat Makassar, produktifitas primer, ikan layang (Decapterus spp.)

\section{PENDAHULUAN}

Pukat cincin merupakan alat utama untuk menangkap ikan pelagis kecil di sekitar Laut Jawa. Sejak 1976 daerah penangkapannya berkembang pesat, di Laut Jawa, Selat Makassar dan Laut Cina Selatan, dan saat ini telah mencapai perairan Sulawesi (Suwarso et al., 2008). Dua species ikan layang (Decapterus russelli dan $D$. macrosoma) merupakan hasil tangkapan utama pukat cincin hampir di setiap daerah penangkapan; secara keseluruhan kontribusinya kira-kira $58 \%$ dari total hasil tangkapan. Perairan Selat Makassar bagian selatan merupakan salah satu tujuan utama penangkapan dan ikan layang memberi kontribusi seki$\operatorname{tar} 43 \%$.

Selat Makassar merupakan perairan yang relatif subur. Penyuburan perairan Selat Makassar terjadi sepanjang tahun baik pada musim barat maupun pada musim timur. Penyuburan pada musim barat terjadi karena adanya run off dari daratan Kalimantan maupun Sulawesi dalam jumlah besar akibat curah hujan yang cukup tinggi, sedangkan pada musim timur terjadi penaikan massa air (upwelling) di beberapa lokasi di Selat Makassar akibat adanya pertemuan massa air dari Samudera Pasifik dengan massa air Laut Jawa dan Laut Flores (llahude, 1978 dalam Afdal dan Riyono, 2004). ENSO (El Niño-Southern Oscillation) sebagai salah satu sumber utama penyebab variabilitas iklim tahunan di suatu daerah. Fenomena ENSO sangat berpengaruh terhadap kondisi lautan dan atmosfer di wilayah tropis. Ikan layang yang merupakan jenis ikan pelagis menurut dugaan akan terpengaruh oleh fenomena ENSO. Penelitian sejenis telah dilakukan oleh Sukresno dan Sunianda (2008) di Laut Banda, hasil penelitian tersebut menunjukkan ENSO memiliki korelasi yang rendah terhadap produktifitas primer. Namun menurut penulis hal tersebut disebabkan adanya jeda waktu (time-lag) pengaruh ENSO terhadap potensi perikanan di laut Banda.

Penelitian ini bertujuan mengetahui pengaruh fenomena ENSO terhadap produktifitas primer dan kelimpahan ikan layang di Selat Makassar bagian selatan berdasarkan data suhu permukan laut (SPL), kandungan klorofil-a dan PAR (Photosyntetic Available Radiation) yang diperoleh dari citra satelit.

\section{METODE PENELITIAN}

\section{Waktu dan Tempat}

Penelitian difokuskan untuk mengkaji kelimpahan ikan layang di perairan Selat Makassar berdasarkan data hasil tangkapan per kapal pukat cincin yang mendarat di Pekalongan selama periode 2006-2007 dan melakukan operasi penangkapan di daerah penangkapan utama di Selat Makassar seperti perairan sekitar Lumu-lumu dan Lari-larian. Posisi daerah penangkapan seperti terlihat pada Gambar 1.

\section{Metode Pengumpulan Data}

Data yang digunakan dalam penelitian ini berupa data hasil tangkapan (per bulan) armada pukat cincin yang fishing base-nya di PPN Pekalongan namun melakukan operasi penangkapan di perairan Selat Makassar untuk periode 2006-2007; Komposit bulanan konsentrasi klorofil-a, suhu permukanan laut dan Photosyntetic Available Radiation (PAR) dari citra MODIS Aqua level $3 \mathrm{http}: / /$ oceancolor. gsfc.nasa.gov, dilengkapi dengan data Multivariate ENSO Index (MEI) bulanan dari NOAA http://www.esrl.noaa.gov. Data hasil tangkapan pukat cincin berasal dari kegiatan monitoring secara harian terhadap kapal-kapal contoh yang bongkar dan lelang di Pekalongan selama periode 2006-2007. Informasi daerah penangkapan diperoleh melalui wawancara dengan nakhoda kapal; lama operasi di laut (dalam hari) dihitung dari catatan keluar-masuk kapal. Jumlah sampel untuk data hasil tangkapan adalah 60 armada pukat cincin, sedangkan sampel citra MODIS berjumlah 24 bulan.

\section{Metode Analisis Data}

\section{Produktifitas primer dengan VGPM}

VGPM (Vertically Generalized Production Model) dikembangkan oleh Behrenfeld dan Falkowski (1997). VGPM berfungsi untuk mengestimasi produktifitas primer bersih untuk permukaan dan hingga kedalam euphotik (kedalaman perairan yang hanya menerima sinar matahari sebesar $1 \%$ ) sebagai fungsi konsentrasi klorofil permukaan, suhu permu-kaan laut, lama penyinaran matahari, flux dari photosynthetically active radiation (pengukuran jumlah penyinaran matahari; penting untuk pertumbuhan 


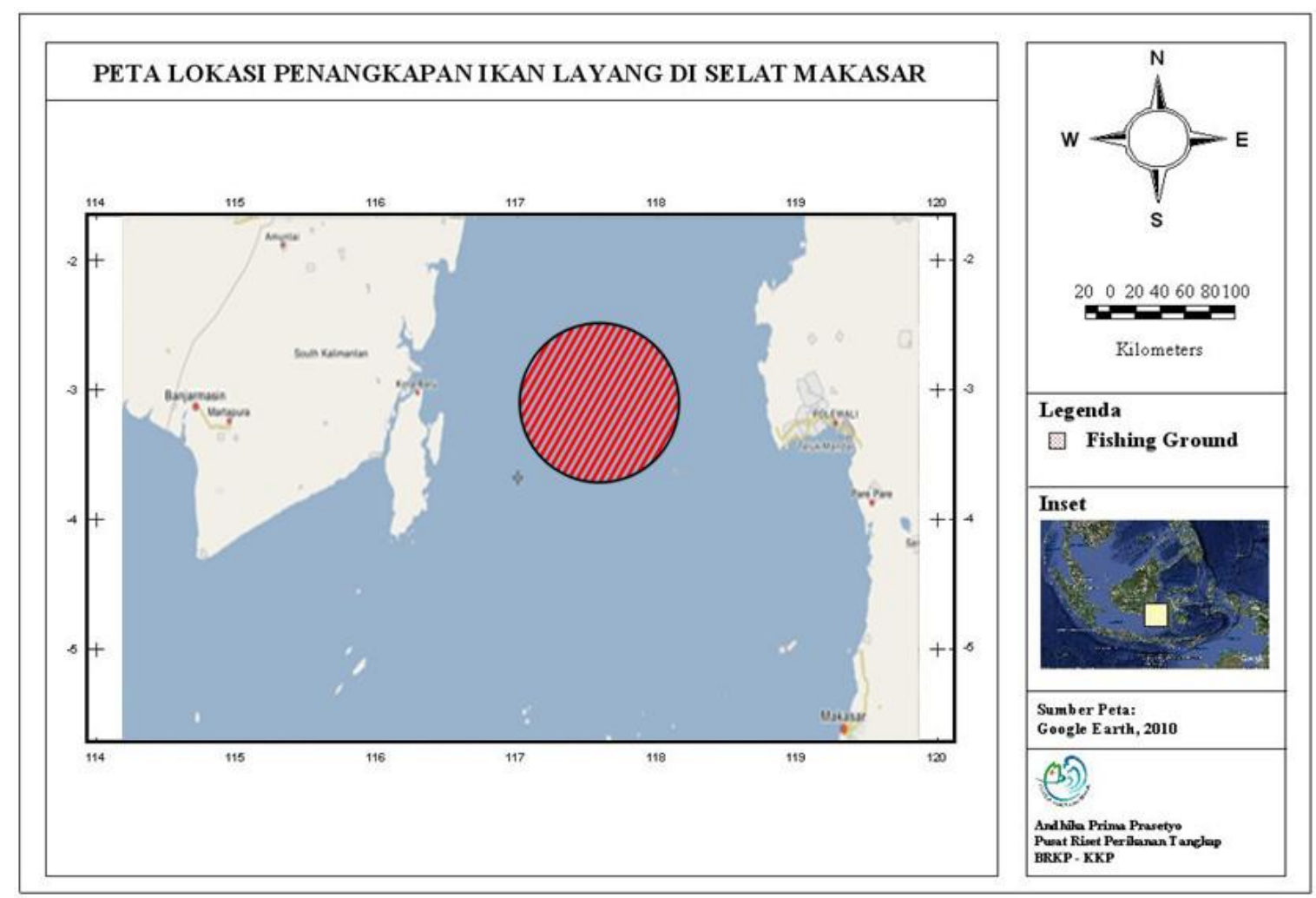

Gambar 1 Peta lokasi penelitian dan posisi daerah penangkapan pukat cincin besar di Selat Makassar.

tanaman) dan kedalaman zona euphotik (diestimasi dari konsentrasi klorofil). Persamaan VGPM dirumuskan sebagai berikut (Behrenfeld dan Falkowski, 1997):

$P P_{e u}=0.66125 \times P_{\text {opt }}^{B} \frac{E_{o}}{E_{o}+4.1} \times C_{S A T} \times Z_{e u} \times D_{I R R}$

Keterangan:

$\mathrm{PP}_{\mathrm{eu}}$ : Fiksasi karbon harian yang terintegrasi dari permukaan hingga zona euphotic (Zeu) $\left(\mathrm{mg} \mathrm{C} / \mathrm{m}^{2}\right)$;

$\mathrm{P}^{\mathrm{B}} \mathrm{Opt}$ : Laju optimal dari fiksasi karbon harian yang terjadi di kolom perairan (mg C $\left.(\mathrm{mg} \mathrm{Chl})^{-1} \mathrm{~h}^{-1}\right]$. $\mathrm{P}^{\mathrm{B}}$ Opt dapat dimodelkan berdasarkan hubungan variasi suhu. Hubungan tersebut dideskripsikan oleh Behrenfeld danFalkowski (1997):

$$
\begin{aligned}
& 1,13 \quad \text { jika } T<-1,0 \\
& P_{\text {opt }}^{B}=\{4,00 \quad \text { jika } T>28,5 \\
& P_{\text {opt }}^{B^{\prime}} \quad \text { Lainnya } \\
& P_{\text {opt }}^{B^{\prime}}=1,2956+2,749 \times 10^{-1} \mathrm{~T}+6,17 \times 10^{-2} T^{2}-2,05 \\
& \times 10^{-2} T^{3}+2,462 \times 10^{-3} T^{4}-1,348 \times 10^{-4} T^{5} \\
& +3,4132 \times 10^{-6} T^{6}-3,27 \times 10^{-8} T^{7}
\end{aligned}
$$

Keterangan:

$E_{0}$ : Nilai PAR permukaan laut harian (Enstein $/ \mathrm{m}^{2} / \mathrm{hr}$ )
$\mathrm{C}_{\text {sat }}$ :'Konsenterasi klorofil permukaan dari satelit yang diturunkan dari water leaving radiance $\left(\mathrm{mgChl} / \mathrm{m}^{3}\right)$. Perhitungan VGPM untuk produktifitas primer global berdasarkan rata-rata $\mathrm{C}_{\text {sat }}$ bulanan

Zeu : Kedalaman zona euphotic yang didefinisikan sebagai kedalaman penetrasi untuk $1 \%$ radiasi permukanan berdasarkan hukum Beer-Lambert. Zeu dihitung dari CSAT menurut Morel dan Berthon (1989):

$Z_{e u}= \begin{cases}568,2\left(C_{\text {tot }}\right)^{-0,746} & \text { jika } Z_{\text {eu }}<102 \\ 200,0\left(C_{\text {tot }}\right)^{-0,293} & \text { jika } Z_{\text {eu }}>102\end{cases}$

$C_{\text {tot }}= \begin{cases}38,0\left(C_{\text {tot }}\right)^{0,425} & \text { jika } C_{\text {tot }}<1,0 \\ 40,2\left(C_{\text {tot }}\right)^{0,507} & \text { jika } C_{\text {tot }} \geq 1,0\end{cases}$

DIRR : Lama penyinaran harian (dalam desimal)

\section{Penghitungan dugaan potensi perikanan}

Fish production model digunakan untuk menduga potensi perikanan berdasarkan hubungan transfer energi antar tingkatan pada rantai makanan. Bila diasumsikan produktifitas primer bernilai $100 \%$, sedangkan efisiensi transfer antar tingkatan rantai makanan sebesar $10 \%$, maka perpindahan energi akibat proses predasi hanya tinggal 10\% (Pauly dan Christensen, 1995). Persamaan fish production model ialah: 


$$
F P=P P \times T E^{(T L-1)}
$$

Keterangan:

FP : Fish Production $\left(\mathrm{mg} \mathrm{C} / \mathrm{m}^{2}\right)$

PP : Primary Production $\left(\mathrm{mg} \mathrm{C} / \mathrm{m}^{2}\right)$

TE : Transfer Efficiency (10\%)

TL : Trophic Level (untuk ikan layang $T L=3$ )

Selanjutnya dari nilai FP, dengan menggunakan faktor konversi dari berat karbon menjadi menjadi massa dengan rasio $9: 1$, sehingga potensi perikanan dapat diduga dengan persamaan berikut:

$$
F B=F P \times 9
$$

Keterangan :

FB : Fish Biomass (dalam ton)

\section{Data oseanografi}

Data suhu permukaan laut (SPL), klorofila dan PAR dari citra AQUA MODIS diolah dengan menggunakan software SeaDAS (Sea WIFS Data Analysis System) 5.4 under Windows. Ketiga data tersebut merupakan data citra komposit bulanan level 3, yakni data yang telah terkoreksi secara atmosferik dan geografik. Algoritma untuk memperoleh nilai SPL pada citra MODIS Aqua ialah algoritma Longwave IR algorithm (LongSST) yang dibuat oleh International MODIS/AIRS Processing Package (IMAPP) pada kanal 31 dan 32. Sedangkan algoritma untuk memperoleh konsentrasi klorofil-a menggunakan algoritma OC3M (Ocean Chlorophyll 3-band).

\section{Algoritma LongSST}

LongSST $=A 1 \times T 11+A 1 \times M C S S T \times(T 11-T 12)+$ $A 3 \times(T 11-T 12) \times(\operatorname{Sec} \theta-1)+A 4$...

Keterangan:

A1, A2, A3 dan A4: koefisien berdasarkan perhitungan data bulanan

MCSST $=B 1 \times T 4+B 2 \times(T 4-T 5)+B 3 \times(T 4-T 5)$

$(\operatorname{Sec} \theta-1)+B 4$

B1, B2, B3 dan B4: koefisien berturut-turut 0,$231 ;-1,20 ;-2,15$ dan 240

\section{- Algoritma OC3M}

$\log [C h l]=A 0+A 1 \times R+A 2 \times R^{2}+A 3 \times R^{3}+A 4 \times X^{4} .(10)$

Dimana: $R=\log \left[\frac{\max \left(R_{r s}(443), R_{r s}(489)\right)}{R_{r s}(555)}\right]$

Keterangan:

A1, A2, A3 dan A4: koefisien berturut-turut 0,$283 ;-2,753 ; 1,457 ; 0,659 ;$ dan $-1,403$

$\mathrm{R}_{\mathrm{rs}}$ 433, 489 dan 555: radiasi remote sensing dari band 433, 489 dan 555

\section{HASIL DAN PEMBAHASAN}

\section{Fluktuasi Kelimpahan Ikan Layang (De- capterus spp.)}

Berdasarkan data pendaratan ikan di PPN Pekalongan, diketahui bahwa jenis ikan layang yang dominan tertangkap di Selat Makassar adalah layang (Decapterus russeli) dan layang abu-abu (D. macrosoma) (Gambar 2). Ikan layang yang merupakan tangkapan utama pukat cicin memiliki kontribusi kira-kira 58\%. Sedangkan perairan Selat Makassar bagian selatan sebagai salah satu tujuan utama penangkapan ikan layang memiliki kontribusi sekitar $43 \%$.

Kategori "layang" pada dasarnya tertangkap sepanjang tahun, fluktuasi terjadi secara bulanan/musiman (Gambar 3); puncak kelimpahan ikan layang di perairan Selat Makassar berlangsung selama 3 bulan, yaitu antara bulan November sampai Januari. Adapun musim paceklik penangkapan ikan layang terjadi sekitar bulan Maret-Mei. Menurut Potier dan Boely (1990) dalam Hendiarti et al. (2005) musim penangkapan sedikit banyak dipengaruhi oleh angin musim (muson). Adapun kelimpahan ikan layang berdasarkan perhitungan VGPM jauh lebih tinggi dibandingkan kelimpahan hasil penangkapan (kelimpahan aktual). Hal tersebut diduga karena keterbatasan kapasitas armada penangkapan, baik berupa aspek teknis penangkapan maupun strategi penangkapan dan faktor-faktor lainnya. Produksi tangkapan ikan layang selama tahun 2007 sebesar $82.280 \mathrm{~kg}$, nilai ini jauh meningkat dibandingkan produksi tahun 2006 yang bernilai $46.179 \mathrm{~kg}$; dengan kata lain terjadi kenaikan produksi sebesar $78,18 \%$. Jika dibandingan antara produksi aktual dan produksi hasil pendugaan dengan VGPM, diketahui tingkat pemanfaatan ikan layang pada tahun 2006 sebesar 8,93\%, sedangkan untuk tahun 2007 sebesar 14,59\%. Nilai pemanfaatan tersebut bukan angka mutlak dan perlu mempertimbangkan pemanfaatan ikan layang di Selat Makassar oleh armada penangkapan lain dan didaratan bukan di PPN Pekalongan. Sehingga perlu kehati-hatian dalam penggunaannya, karena ada bias yang besar. Walaupun begitu nilai tersebut tetap bisa dijadikan bahan diskusi dalam rangka pengelolaan perikanan.

Terkait dengan musim ikan di Laut Jawa, musim puncak ikan layang di Selat Makassar lebih lambat sekitar dua bulan dibanding musim puncak kelimpahan di Laut Jawa (perairan sekitar Kepulauan Masalembo dan pulau Matasirih) yang berlangsung pada musim peralihan 2 (September-November) dimana daerah penangkapan banyak dilakukan di perairan seki- 

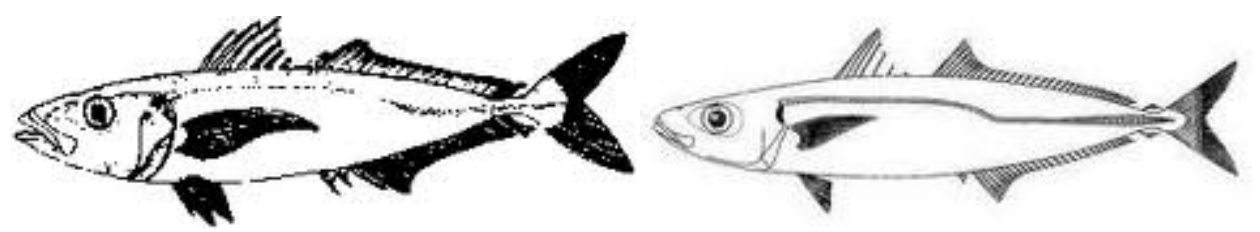

Gambar 2 [a] Layang (Decapterus russelli) dan [b] layang deles (D. macrosoma).

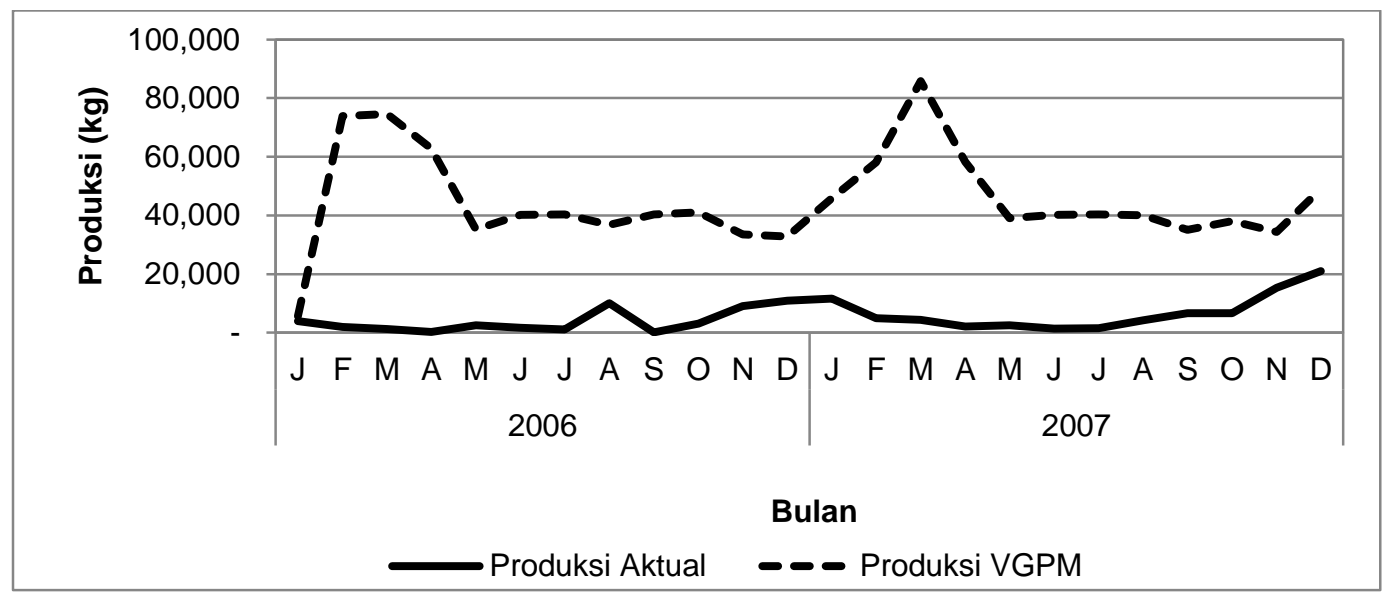

Gambar 3 Kelimpahan ikan layang aktual dan kelimpahan berdasarkan VGPM periode 2006-2007

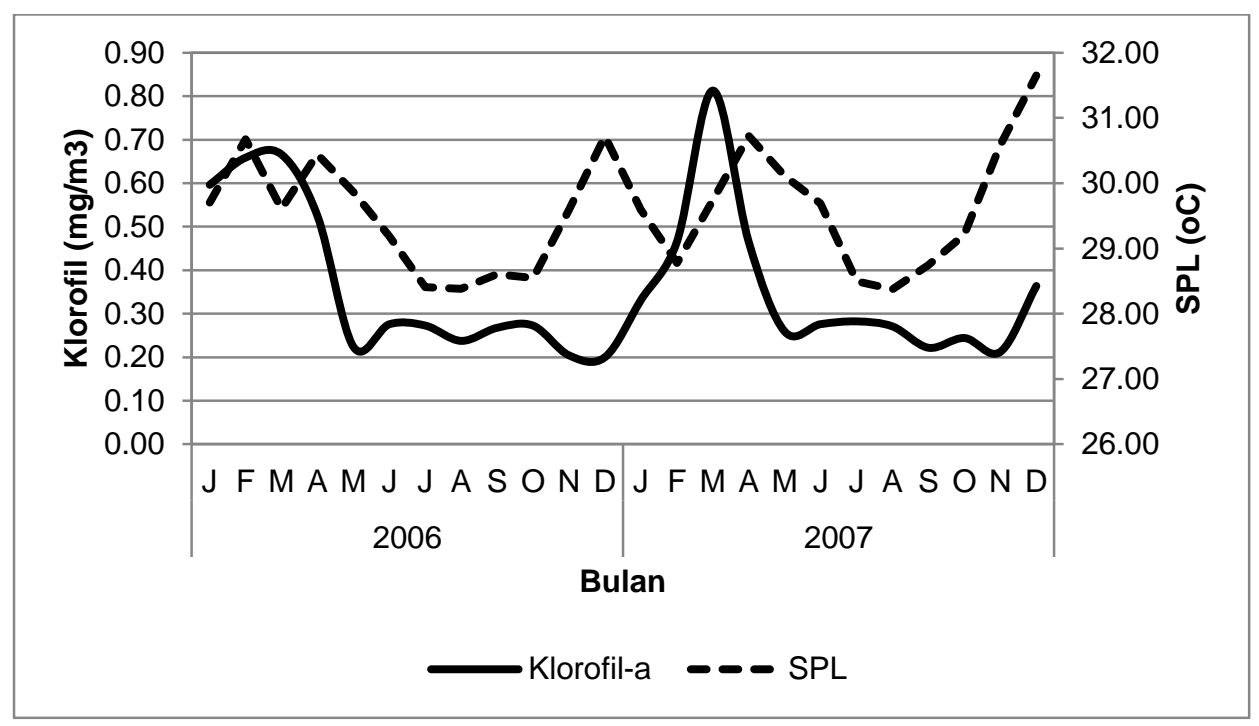

Gambar 4 Hubungan konsentrasi klorofil-a dengan suhu permukaan laut.

tar Masalembo dan Matasiri (Potier dan Sadhotomo, 2003). Selisih musim puncak tersebut diduga terjadi karena adanya spawning migration ikan layang dari timur Laut Jawa ke arah barat Selat Makassar. Indikasi tersebut berda-sarkan temuan Potier dan Sadhotomo (2003), bahwa adanya pergeseran ukuran ikan layang yang berhubungan dengan tingkat kematangan gonad ikan layang. Fluktuasi produksi menurut Atmaja et al. (1986) berhubungan dengan musim dan kapasitas armada penangkapan yang dikuti dengan perubahan daerah penangkapan dan strategi penangkap- an. Hendiarti et al. (2005) menambahkan variasi kelimpahan ikan hasil tangkapan tahunan ditentukan oleh beberapa faktor, yakni proses oseanografi dan antropogenik seperti kemampuan penangkapan dan kapasitas penangkapan.

\section{Fluktuasi Suhu Permukaan Laut dan KIo- rofil-a Berdasarkan Citra Satelit}

Analisis data citra AQUA-MODIS menunjukkan suhu permukaan laut di Selat Makassar selama periode 2006-2007 berkisar antara $28,38-31,65^{\circ} \mathrm{C}$. Fluktuasi suhu permukaan laut 
selama 2006-2007 ditunjukkan pada Gambar 4. Hasil perekaman suhu permukaan laut selama bulan November-Januari diperlihatkan pada Gambar 5. Dari fluktuasi suhu permukaan laut secara bulanan tersebut terlihat bahwa selama periode November-Januari terlihat cenderung lebih hangat. Sebaran klorofil-a di Selat Makassar selama periode 2006-2007 hasil citra Aqua MODIS menunjukkan bahwa konsentrasi klorofil-a berkisar antara 0,20-0,81 mg/m³. Hasil perekaman konsentrasi klorofil-a di permukaan selama bulan November-Januari diperlihatkan pada Gambar 6. Konsentrasi klorofil-a tertinggi terjadi pada periode Februari-April tiap tahunnya, dimana puncaknya terjadi pada bulan Maret. Puncak konsentrasi klorofil-a pada bulan Maret tahun 2006 dan 2007 berturut-turut sebesar $0,67 \mathrm{mg} / \mathrm{m}^{3}$ dan $0,81 \mathrm{mg} / \mathrm{m}^{3}$.

Secara umum hasil pengolahan data menunjukkan hubungan suhu permukaan dan kandungan klorofil-a berkorelasi positif, dimana fluktuasi suhu permukaan laut diikuti oleh fluktuasi kandungan klorofil-a (Gambar 7). Terdapat selang waktu (time-lag) sekitar 1-2 bulan antara terjadinya puncak suhu permukaan dengan puncak kandungan klorofil-a. Hal ini berkebalikan dengan pendapat Amri et al. (2005) yang menyatakan indikator terjadinya upwelling ditunjukkan dengan temuan sebaran SPL rendah diikuti dengan tingginya kandungan klorofil-a. Hal ini bisa dijelaskan, perairan Selat Makassar yang dikaji dalam penelitian ini ialah perairan yang berada di tengah-tengah perairan Selat Makassar, dimana pengaruh coastal upwelling tidak terjadi. Dugaan pergerakan ikan layang dengan tujuan pemijahan dari perairan timur Laut Jawa ke arah barat Selat Makassar disebabkan terjadinya pengayaan nutrien di Selat Makassar ( 2 bulan lebih lambat dibandingkan puncak kelimpahan ikan layang). Adapun bulan dimana suhu permukaan tinggi terjadi bertepatan dengan kelimpahan ikan layang, diduga kisaran suhu tersebut mendukung proses pemijahan ikan layang.

Menurut Tomascik et al. (1997) dalam Afdal dan Riyono (2003) suhu mempengaruhi proses fotosintetis di laut baik secara langsung maupun tidak langsung. Pengaruh suhu secara langsung yakni mengontrol reaksi kimia enzimatik dalam proses fotosintetis, sedangkan pengaruh secara tidak langsung yakni dalam merubah struktur hidrologi kolom perairan yang dapat mempengaruhi distribusi fitoplankton. Secara umum, laju fotosintetis fitoplankton meningkat dengan meningkatnya suhu perairan, namun akan menurun secara drastis setelah mencapai suhu tertentu. Hal ini disebabkan setiap spesies fitoplankton selalu beradaptasi terhadap suatu kisaran suhu tertentu (Afdal dan Riyono, 2003).

\section{Dugaan Hubungan Kelimpahan dengan Fenomena ENSO}

Berdasarkan data Multivariat Indeks ENSO dari NOAA, diketahui bahwa pada periode 2006-2007, indeks ENSO tertinggi terjadi pada bulan November 2006 sebesar 1,29 dan terendah terjadi pada bulan Desember 2007 sebesar -1,14. Namun secara umum nilai ENSO pada periode 2006-2007 tergolong normal, karena menurut Antoro percomm (2010) kategori ENSO diatas nomal ialah saat indeks ENSO bernilai lebih besar dari 3 atau lebih rendah dari -3. Analisis hubungan produksi layang terhadap fenomena ENSO menunjukkan pada tahun 2006 secara umum pola produksi ikan layang sejalan dengan fenomena ENSO (Gambar 8). Produksi layang rendah disaat indeks ENSO rendah dan saat musim puncak layang indeks ENSO bernilai tinggi. Namun pengaruh ENSO terjadi sebaliknya pada periode tahun 2007, dimana produksi ikan layang yang tinggi diikuti oleh indeks ENSO yang rendah.

Pengaruh ENSO terhadap konsentrasi klorofil-a menunjukkan ketidakkonsistenan saat ENSO rendah konsentrasi klorofil-a di Se-lat Makassar ada yang menjadi tinggi pada bu-lan Januari 2006 dan Desember 2007, namun menjadi rendah pada bulan November 2006. Pola yang sama terjadi antara ENSO terhadap SPL, saat ENSO rendah SPL di Selat Makassar ada yang menjadi tinggi (bulan Januari 2006 dan Desember 2007) dan adapula yang menjadi rendah (bulan Oktober 2006) (Gambar 9).

Terdapat indikasi ENSO berpengaruh secara tidak langsung terhadap produksi ikan layang, konsentrasi klorofil-a dan suhu permukaan laut di Selatan Makassar. Hal tersebut diperkuat dengan kajian yang dilakukan oleh Sadhotomo dan Durand (1996) mengenai pengaruh kejadian El Niño di Pasifik bagian barat terhadap Laut Jawa. Hasilnya menunjukkan ENSO berpengaruh secara tidak langsung terhadap kondisi hidrografi Laut Jawa, yakni berupa ketinggian muka laut dan sikulasi global. Indikasi pengaruh ENSO terhadap pergerakan massa air di Laut Jawa (contoh: kepulauan Indonesia bagian timur) bahwa massa air masuk jauh ke dalam dan tetap diam dalam waktu yang lama dibandingkan saat tahuntahun normal.

Pengaruh kejadian angin, arus dan upwelling tidak hanya berpengaruh terhadap produktifitas primer, tetapi juga berpengaruh 


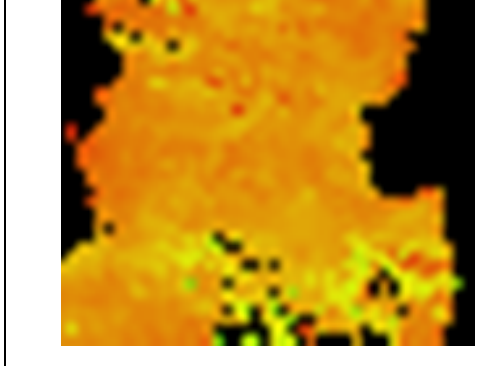

Jan 2006

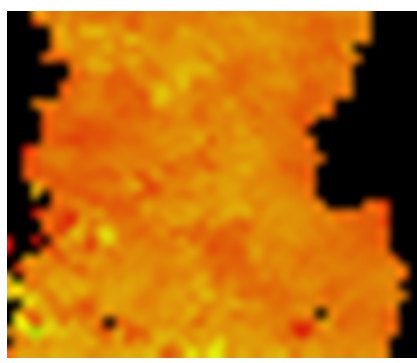

Jan 2007

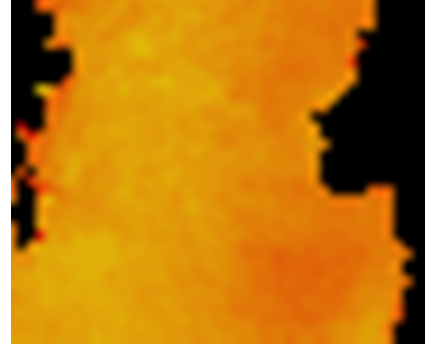

Nov 2006

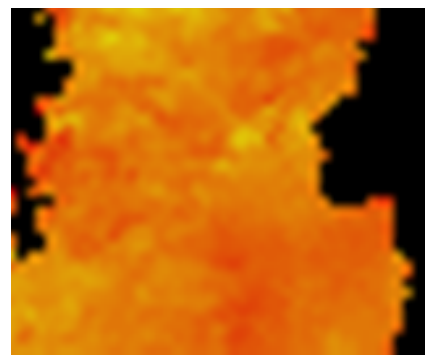

Nov 2007

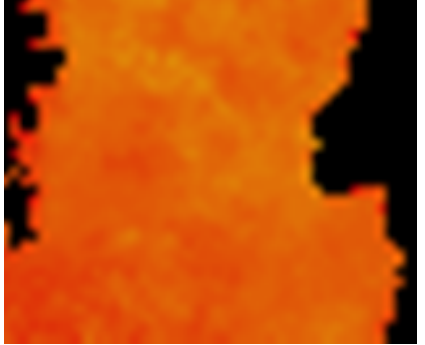

Des 2006

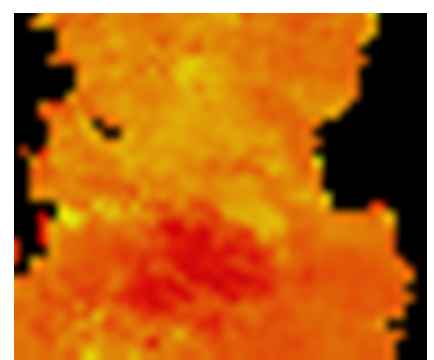

Des 2007

Sea Surface Temperature $\left({ }^{\circ} \mathrm{C}\right)$

$\begin{array}{llllllllllllllllllllllllll}-2 & 0 & 2 & 4 & 6 & 8 & 10 & 12 & 14 & 16 & 18 & 20 & 22 & 24 & 26 & 28 & 30 & 32 & 34 & 36 & 38 & 40 & 42 & 44\end{array}$

Gambar 5 Citra suhu permukaan laut (SPL) bulan November-Januari di Selat Makassar bagian selatan (2006-2007).

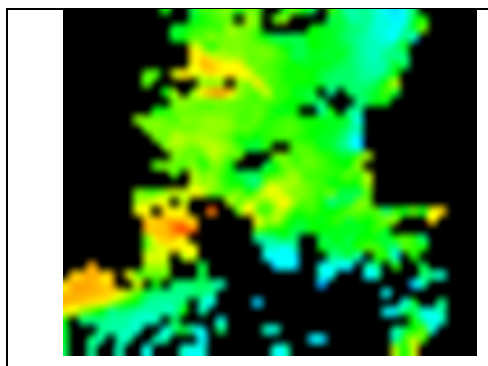

Jan 2006

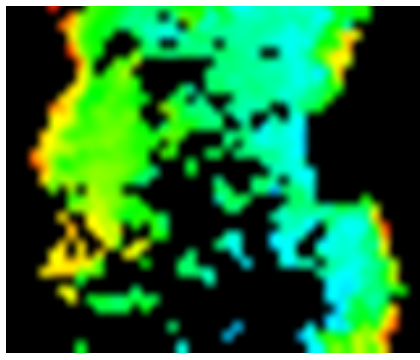

Jan 2007

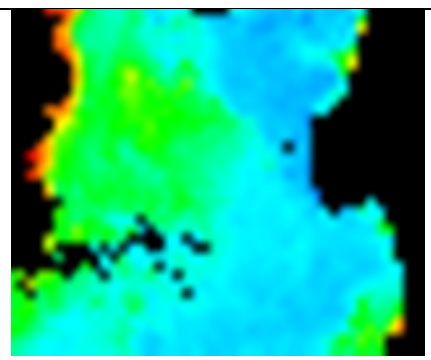

Nov 2006

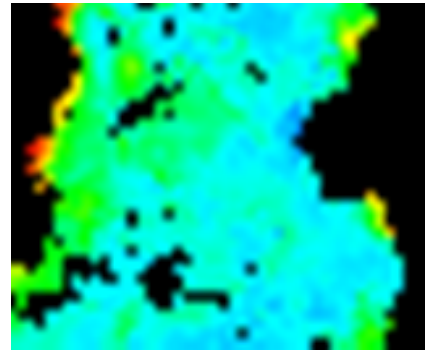

Nov 2007

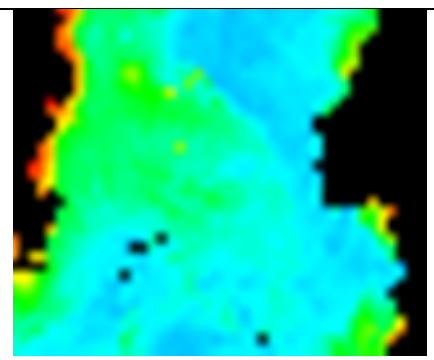

Des 2006

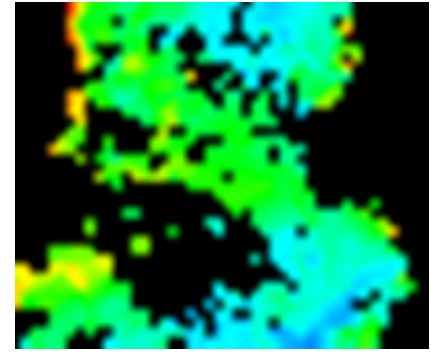

Des 2007

Chlorophyll a concentration $\left(\mathrm{mg} / \mathrm{m}^{3}\right)$

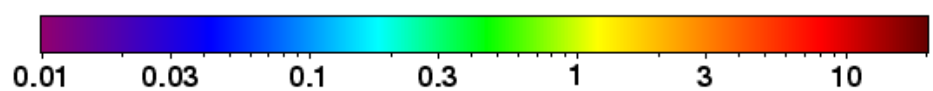

Gambar 6 Citra klorofil-a pada bulan November-Januari di Selat Makassar bagian selatan, 2006-2007. 

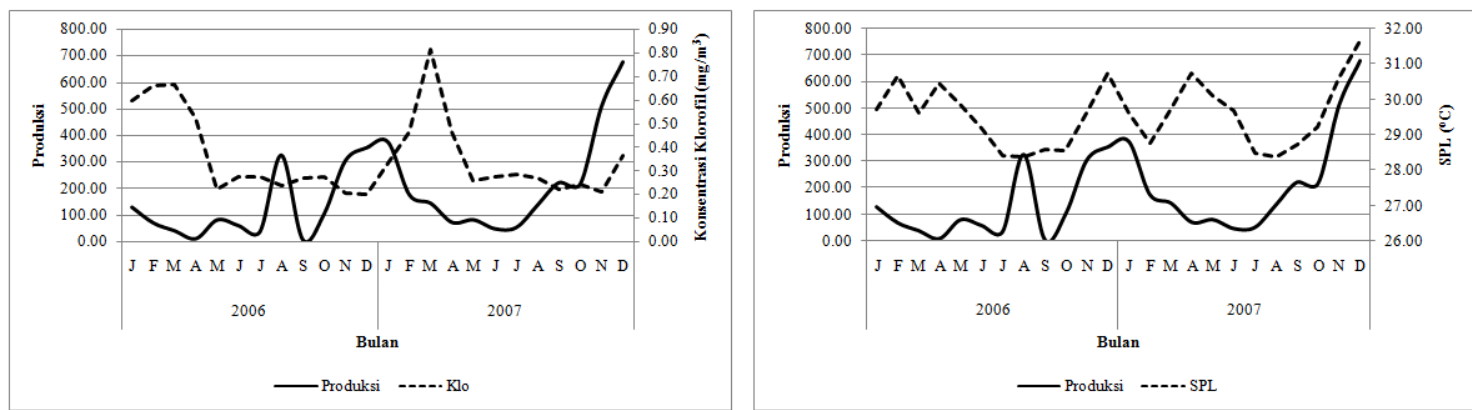

Gambar 7 Hubungan produksi ikan layang terhadap klorofil-a dan SPL.

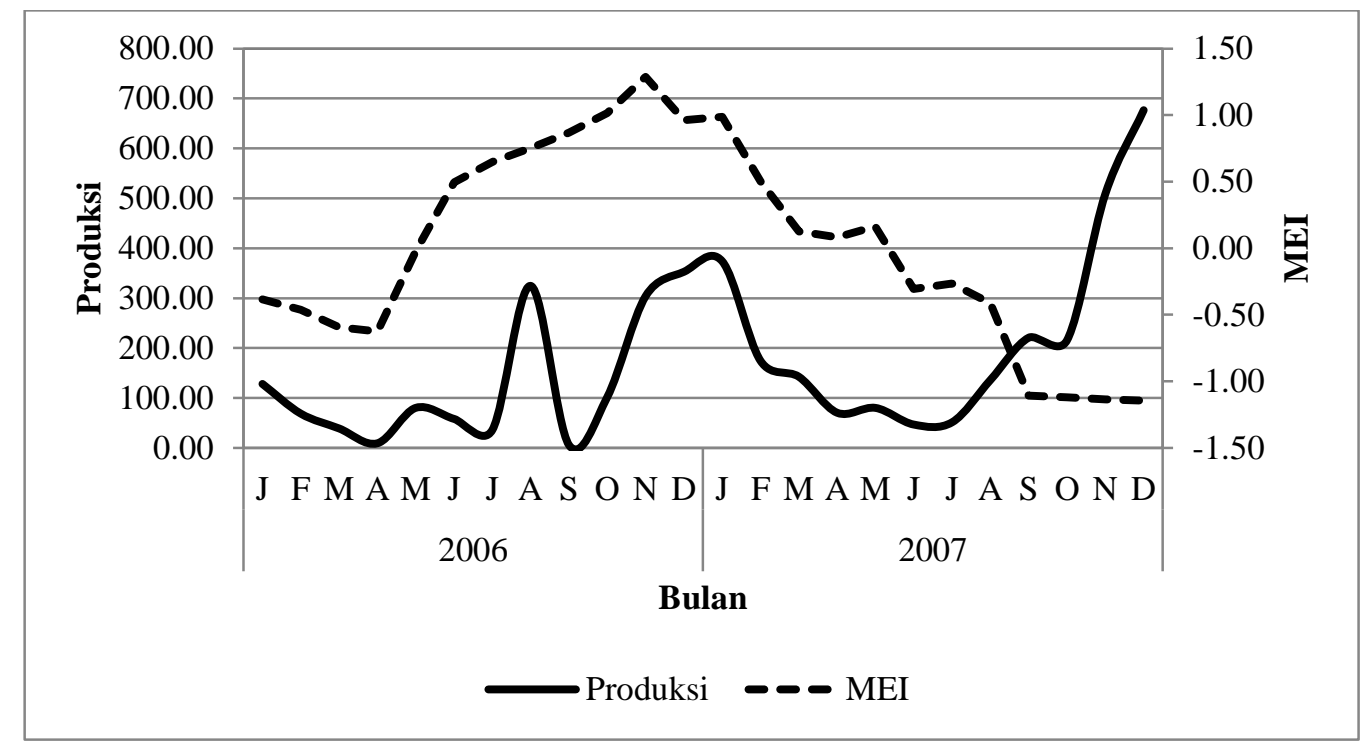

Gambar 8 Pengaruh ENSO terhadap produksi aktual ikan layang.
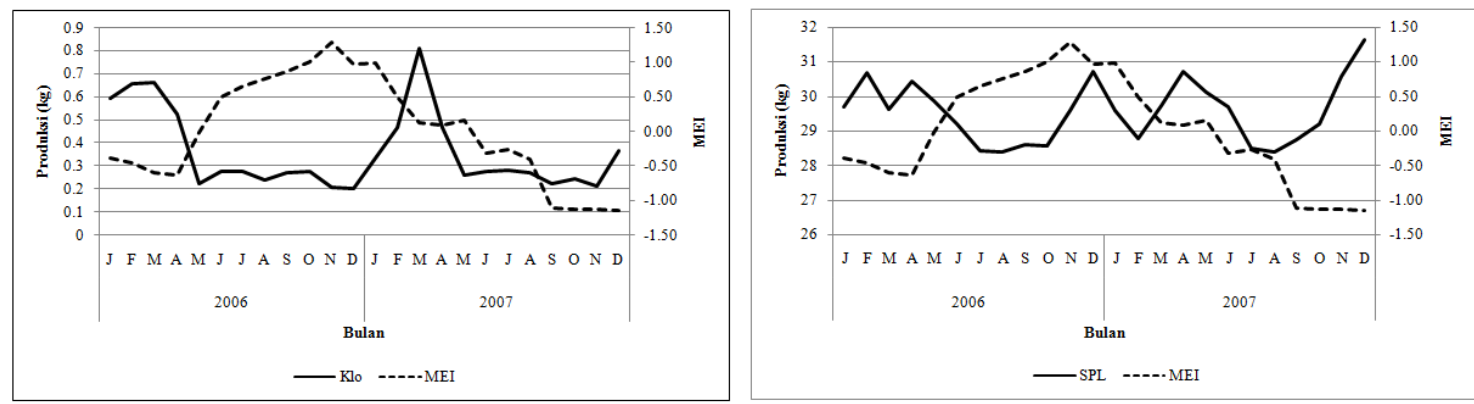

Gambar 9 Pengaruh ENSO terhadap konsentrasi klorofil-a dan SPL.

terhadap perikanan, iklim dan keselamatan umat manusia (Castro dan Huber, 1997). Fenomena ENSO merupakan faktor utama penyebab variasi iklim tahunan di dunia (Lehodey, 2000). Berdasarakan penelitian Harley et al. (2006) menunjukkan variabilitas iklim dan lingkungan berpengaruh terhadap distribusi, migrasi dan kelimpahan ikan dan kehidupan laut lainnya. Pengaruh ENSO secara nyata memiliki dampak terhadap dinamika populasi tuna di Samudera Pasifik bagian tropis (Lahodey et al., 2006). Saat terjadi ENSO tingkat dasar dari rantai makanan akan berubah secara drastis. Hal tersebut berpengaruh terhadap habitat tuna, perubahan migrasi, berpengaruh terhadap tingkat ketahanan hidup larva dan proses rekruitmen, hingga jumlah stok tuna yang bisa dieksploitasi tiap tahun (Ciannelli et al., 2005).

Studi mengenai pengaruh ENSO terhadap tuna menunjukkan tidak semua tuna merespon siklus ENSO dengan cara yang sama (Lahodey, 2000). Skipjack dan yellowfin tuna bergerak kearah timur saat kejadian El Niño. Hal tersebut berhubungan dengan posisi zona konvergen oseanik dimana arus dan kolam 
hangat bertemu daerah dingin, perairan yang kaya akan nutrein bergerak dari Pasifik timur (Hamnett dan William, 1996). Sebaliknya pola yang berlawanan ditujukkan oleh albacore dari Pasifik Selatan, dimana proses rekruitmen yang rendah terjadi saat El Niño dan tinggi saat kejadian La Niña (Ciannelli et al., 2005).

Sebagai informasi ENSO juga mempengaruhi karakteristik Arus Lintas Indonesia (AR LINDO) yang juga melewati Selat Makassar (Sofian dan Kozai, 2005). Ffield et al. (2000) men-jelaskan SOI (Southern Oscillation Index) ber-hubungan erat dengan lapisan termoklin. Ber-dasarkan hubungan tersebut pada saat periode El Niño transpor antar-samudera menjadi ren-dah dan tinggi saat periode $\mathrm{La}$ Niña. Bray et al. (1996) dalam Sofian dan Kozai (2005) menemu-kan bahwa ada korelasi antara SOI dan anoma-li muka laut (sea level anomaly) yang tinggi un-tuk lautan di bagian timur Indonesia dan lemah untuk lautan di bagian barat Indonesia.

\section{KESIMPULAN}

Puncak kelimpahan ikan layang (D. russelli dan $D$. macrosoma) di daerah penangkapan utama di Selat Makassar (sekitar Larilarian dan Lumu-lumu) terjadi sekitar 3 bulan antara November-Januari.

Persentase pemanfaatan ikan layang pada periode tahun 2006-2007 berturut-turut sebesar $8,93 \%$ dan $14,59 \%$ terhadap kelimpahan sumber daya ikan pada trofik level 3.

Berdasarkan data citra satelit 2006-2007, rata-rata suhu permukaan laut dan kandungan klorofil-a berfluktuasi menurut musim; di daerah penangkapan utama suhu permukaan berkisar antara $28,38-31,65^{\circ} \mathrm{C}$, konsetrasi klorofil-a berkisar antara $0,22-0,81 \mathrm{mg} / \mathrm{m}^{3}$, nilai PAR berkisar antara 36,33-52,83 Enstein $/ \mathrm{m}^{2} / \mathrm{hr}$. Suhu permukaan yang lebih hangat terjadi pada sekitar puncak kelimpahan ikan layang (NovemberJanuari), konsentrasi klorofil-a tertinggi terjadi antara Februari-April; nilai PAR tertinggi terjadi antara September-November.

ENSO berpengaruh secara tidak langsung terhadap konsentrasi klorofil dan SPL yang berhubungan produksi ikan layang.

\section{DAFTAR PUSTAKA}

Afdal dan S. Hadi Riyono. 2004. Sebaran Klorofil-a Kaitannya dengan Kondisi Hidrologi di Selat Makassar. Oseanologi dan Limnologi di Indonesia, 36: 69-82.
Amri, K., Suwarso dan Awaludin. 2005. Kondisi Hidrologis dan Kaitannya dengan Hasil Tangkapan Ikan Malalugis (Decapterus macarellus) di Perairan Teluk Tomini. Jurnal Penelitian Perikanan Indonesia 11(6): 14 hal.

Atmaja S.B., Suwarso and Nurhakim S. 1986. Hasil Tangkapan pukat cincin menurut musim dan daerah penangkapan di laut Jawa. Jurnal Penelitian Perikanan Laut 36: 57-65.

Behrenfeld dan Falkowski. 1997. A consumer's guide to phytoplankton primary productivity models. Limnology and Oceanography, 42 (7). 1479-1491 pp.

Morel dan Berthon. 1989. Surface pigments, algal biomass profiles, and potential production of the euphotic layer: Relationships reinvestigated in view of remote-sensing applications. Limnology and Oceanography. 34. 1545-1562 pp.

Castro, P. dan M. E. Huber. 1997. Fisheries Biology: The El Niño-Southern Oscillation. New York: The McGraw-Hill Companies. 329-331 pp..

Ciannelli L., D.Ø. Hjermann, P. Lehodey, G. Ottersen, J.T. Duffy-Anderson. N.C. Stenseth. 2005. Chapter 12: Climate Forcing, Food Web Structure and Community Dynamics in Pelagic Marine Ecosystems. Belgrano, A. U. Scharler, J. Dunne and B. Ulanowicz (Eds.). Aquatic Food Webs: An Ecosystem Approach. Oxford University Press: 143-169.

Ffield, A., K. Vranes, A. L. Gordon and R. D. Susanto. 2000. Temperature vaiability within Makassar strait. Geophysical Research Letters, 27(2): 237-240 pp.

Hamnett, Michael P. and William Sam Pintz. 1996. The Contribution of Tuna Fishing and Transshipment to the Economies of American Samoa, the Commonwealth of the Northern Mariana Islands, and Guam. SOEST Publication 96-05, JIMAR Contribution 96-303.

Harley, C.D.G., Hughes, A.R. Hultgren, K.M., Miner, B.G., Sorte, C.J.B., Thornber, C.S., Rodriguez, L.F., Tomanek, L., Williams, S. 2006. The Impacts of Climate Change in Coastal Marine Systems. Ecology Letters 9: 228-241.

Hendiarti, N., Suwarso, E. Aldrian, K. Amri, R. Andiastuti, S. I. Shacoemar dan I. B. Wahyono. 2005. Seasonal Variation of Pelagic Fish Catch Around Java. Oceanography 18 (4): 112-123. 
Lehodey, P. 2000. Impacts of the El Niño Southern Oscillation on Tuna Populations and Fisheries in the Tropical Pacific Ocean. $13^{\text {th }}$ Standing Committee on Tuna and Billfish, Noumea, 5-12 July 2000, Secretariat of the Pacific Community, Noumea, Working Paper SCTB13-RG-1. 2010.

Lehodey P., J. Alheit, M. Barange, T. Baumgartner, G. Beaugrand, K. Drinkwater K., J.-M. Fromentin, S. R. Hare, G. Ottersen, R. I. Perry., C. Roy, C.D. van der Lingen, and F. Werner. 2006. Climate Variability, Fish and Fisheries. Journal of Climate 19 (20): 5009-5030.

Potier, M. and B. Sadhotomo. 2003. BIODYNEX $2^{\text {nd }}$ Edition: Exploratory Scheme for The Recruitment and Migration of The
Main Pelagic Species. The Agency for Marine and Fisheries Research, Ministry of Marine Affairs and Fisheries.155-168.

Sadhotomo, B. dan J.R. Durand. 1996. General Features of Java Sea Ecology. Proceeding of Acoustics Seminar Akustikan, Bandungan 27-29 May 1996. ISBN No. 979-8186-64-8. 43-55 pp.

Sofian, I. dan K. Kozai. 2005. Literaure review of sea level variation in the Makassar Strait. Faculty of Marine Science, Kobe Uni-vesity no. 2. 111-117 pp.

Suwarso, A. Zamroni dan Wudianto. 2008. Biologi Reproduksi dan Dugaan Musim Pemijah-an Ikan Pelagis Kecil di Laut Cina Selatan. Jurnal Penelitian Perikanan Indonesia 14(4): 16 hal. 